\title{
Genome-scale metabolic modeling underscores the potential of Cutaneotrichosporon oleaginosus ATCC 20509 as a cell factory for biofuel production
}

\author{
Nhung Pham¹, Maarten Reijnders ${ }^{1,4}$, Maria Suarez-Diez ${ }^{1} \mathbb{D}$, Bart Nijsse ${ }^{1}$, Jan Springer ${ }^{2}$, Gerrit Eggink ${ }^{2,3}$ \\ and Peter J. Schaap ${ }^{1^{*}}$ (i)
}

\begin{abstract}
Background: Cutaneotrichosporon oleaginosus ATCC 20509 is a fast-growing oleaginous basidiomycete yeast that is able to grow in a wide range of low-cost carbon sources including crude glycerol, a byproduct of biodiesel production. When glycerol is used as a carbon source, this yeast can accumulate more than $50 \%$ lipids (w/w) with high concentrations of mono-unsaturated fatty acids.
\end{abstract}

Results: To increase our understanding of this yeast and to provide a knowledge base for further industrial use, a FAIR re-annotated genome was used to build a genome-scale, constraint-based metabolic model containing 1553 reactions involving 1373 metabolites in 11 compartments. A new description of the biomass synthesis reaction was introduced to account for massive lipid accumulation in conditions with high carbon-to-nitrogen (C/N) ratio in the media. This condition-specific biomass objective function is shown to better predict conditions with high lipid accumulation using glucose, fructose, sucrose, xylose, and glycerol as sole carbon source.

Conclusion: Contributing to the economic viability of biodiesel as renewable fuel, C. oleaginosus ATCC 20509 can effectively convert crude glycerol waste streams in lipids as a potential bioenergy source. Performance simulations are essential to identify optimal production conditions and to develop and fine tune a cost-effective production process. Our model suggests ATP-citrate lyase as a possible target to further improve lipid production.

Keywords: Genome-scale metabolic model, Cutaneotrichosporon oleaginosus ATCC 20509, Lipid accumulation, Crude glycerol, Biodiesel production, Flux balance analysis, Oleaginous yeast

\section{Background}

Microbial lipids produced by oleaginous yeasts are promising sources for oleochemical replacements of hazardous petrochemicals in fuels and chemicals $[1,2]$. For the establishment of an economical bio-based utilization, cost-effective production is key. Of the fewer than 30

\footnotetext{
*Correspondence: peter.schaap@wur.nl

${ }^{1}$ Laboratory of Systems and Synthetic Biology, Wageningen University \& Research, Wageningen, the Netherlands
}

Full list of author information is available at the end of the article known oleaginous yeasts, the top five most studied species are Yarrowia lipolytica, Rhodotorula glutinis, Rhodosporidium toruloides, Cutaneotrichosporon oleaginous, and Lipomyces starkeyi [1]. The profile of lipids and fatty acids produced by these yeasts varies, but under natural conditions they can, on average, accumulate lipids up to $40 \%$ of their weight $[3,4]$. A lipid content of up to $70 \%$ can be obtained if in the presence of a carbon source, an essential nutrient is depleted [4]. Under such conditions, excess carbon will be re-routed to storage compounds, being lipids in oleaginous yeasts $[3,5]$. Nitrogen

c) The Author(s) 2021. This article is licensed under a Creative Commons Attribution 4.0 International License, which permits use, sharing, adaptation, distribution and reproduction in any medium or format, as long as you give appropriate credit to the original author(s) and the source, provide a link to the Creative Commons licence, and indicate if changes were made. The images or other third party material in this article are included in the article's Creative Commons licence, unless indicated otherwise in a credit line to the material. If material is not included in the article's Creative Commons licence and your intended use is not permitted by statutory regulation or exceeds the permitted use, you will need to obtain permission directly from the copyright holder. To view a copy of this licence, visit http://creativeco mmons.org/licenses/by/4.0/. The Creative Commons Public Domain Dedication waiver (http://creativecommons.org/publicdomain/ zero/1.0/) applies to the data made available in this article, unless otherwise stated in a credit line to the data. 
limitation, often referred to as a high $\mathrm{C} / \mathrm{N}$ ratio has been shown to be the most efficient inducer of such lipid accumulation [4].

As input materials are one of the main contributors to production cost [6], for an economically feasible process, a natural capacity for high lipid biosynthesis may not be enough. Oleaginous yeasts are able to use a range of alternative sugars for lipid production (Table 1). Among them, C. oleaginosus appears to be one of the most accommodating and is able to grow in a wide range of industrially interesting operational conditions such as in food waste and municipal wastewater streams [7], whey permeate [8], office paper production waste streams $[9,10]$, spent yeast lysate from brewery industry and crude glycerol from biodiesel production $[11,12]$. Lipid production by this yeast has been studied for at least two decades $[4,8$, 13-16] and when growing on crude glycerol, C. oleaginosus can accumulate more lipid content than many other yeasts, microalgae or molds (Table 1). Owing to these advantages, $C$. oleaginosus is flagged as one of the most cost-effective and versatile cell factories for de novo lipid production $[1,17]$. Especially when the inexpensive waste product from biodiesel production, crude glycerol, is becoming abundantly available, this organism could play a major role in further upcycling of the biodiesel process, as lipids derived from C. oleaginosus grown on glycerol have high concentrations of monounsaturated fatty acids (MUFA) [18]. MUFAs are excellent biodiesel components due to their low temperature fluidity and oxidative stability [18].

C. oleaginosus is a basidiomycete yeast of the Tremellomycetes class and recently added to the Cutaneotrichosporon genus [19]. Taxonomically, it has been reclassified and renamed several times as Apiotrichum curvatum, Cryptococcus curvatus, Trichosporon cutaneum, Trichosporon oleaginosus, and Cutaneotrichosporon curvatum $[11,12]$. In this study, we will refer to it as Cutaneotrichosporon oleaginosus ATCC20509 [20, 21]. The yeast can metabolize a wide range of oligo- and monomeric sugars such as cellobiose, xylose, sucrose, lactose, and glucose [22]. Xylose is efficiently metabolized via the phosphoketolase pathway and partly via the pentose phosphate pathway $[11,23]$. Both pathways produce pyruvate as intermediate for further metabolic processes [11].

Despite many efforts spent on studying this yeast, its use for the production of lipids from glycerol is still far from optimized [1, 10, 24]. Recently, a response surface method was used to design experiments to optimally explore the relationship between the carbon-to-nitrogen ratio in the medium and lipid production and to guide the design of optimal production media for C. oleaginosus ATCC20509 [25]. However, the translation from the genotype to a (preferred) phenotype [i.e. high lipid production], is typically a multi-factorial process depending on the growth medium, culture conditions, strain specificity and the interplay among these factors. Hence, a predictive constraint-based, genome-scale model of metabolism (GEM), along with genetic accessibility tools [26] will provide new avenues towards reaching the full potential of C. oleaginosus ATCC 20509 as a lipid producer [11].

By drawing upon a thorough functional re-annotation of its genome, we have built a GEM for C. oleaginosus ATCC 20509. The model is named $i$ NP636_Coleaginosus ATCC20509, expanding the usual naming convention for GEMs [27] by including information on the organism considered to enhance recognition. Subsequently, the model was used to investigate optimal lipid production in glycerol.

\section{Results and discussion Annotation}

One of the major bottlenecks in eukaryotic genome annotation is the identification of exon-intron boundaries. In this regard, transcriptome data can provide a good basis for predicting introns. We therefore collected transcriptome data (RNAseq) of C. oleaginosus ATCC 20509 from two conditions and used it to structurally

Table 1 Lipid yields obtained by oleaginous yeasts

\begin{tabular}{|c|c|c|c|}
\hline Organism & Yield $^{a}$ & Carbon source & Reference \\
\hline Yarrowia lipolytica & 0.27 & Glucose & [80] \\
\hline Yarrowia lipolytica & 0.10 & Crude glycerol & [81] \\
\hline Rhodosporidium toruloides & 0.29 & Lignocellulosic hydrolysates & [82] \\
\hline Rhodotorula glutinis & 0.18 & Molasses & [83] \\
\hline Lipomyces starkeyi & 0.24 & Glucose & [84] \\
\hline Cutaneotrichosporon oleaginosus & 0.22 & Glucose & [85] \\
\hline Cutaneotrichosporon oleaginosus & 0.29 & Whey permeate & [8] \\
\hline Cutaneotrichosporon oleaginosus & 0.27 & Crude glycerol & [18] \\
\hline
\end{tabular}

${ }^{a}$ g-lipid/g-substrate 
annotate genome sequence MATS00000000.1 of C. oleaginosus ATCC 20509 [28].

BRAKER1 [29] predicted 7861 protein coding genes. Of these, 7474 genes are directly supported by RNAseq with more than 50 read counts per million (CPM). Among the protein-coding genes, 5621 proteins with functional protein domains (Pfam release 31) and 2358 with a full unique Enzyme Commission (EC) number could be predicted. A summary is provided in Table 2. A complete annotation is provided in Additional file 1.

\section{Lipid synthesis pathways}

C. oleaginosus ATCC 20509 metabolizes sugars by using standard central metabolic pathways including glycolysis, pentose phosphate pathway and the citric acid (TCA) cycle. The yeast metabolizes xylose via the phosphoketolase pathway and partly via the pentose phosphate pathway $[11,23]$. These pathways provide the precursors and energy required for lipid biosynthesis. Lipid biosynthesis can be divided into three steps: formation of fatty acids, synthesis of triacylglyceride (TAG), and synthesis of phospholipids (Fig. 1).

\section{Formation of fatty acids}

In yeasts, fatty acids can derive from either a de novo synthesis pathway or from hydrolysis of complex lipids and delipidation of proteins, and from hydrolysis of external fatty acids sources [30]. De novo fatty acid synthesis generally occurs in the cytosol [4], and in some cases, in the mitochondrion [31]. This pathway produces saturated fatty acids up to $16 \mathrm{C}$ atoms while further elongation and desaturation takes place in the endoplasmic reticulum (ER) $[4,32]$. The process is catalyzed by the multi-enzyme fatty acid synthetase complex (FAS) [4]. We found multiple genes, g2870.t1, g5734.t1, g570. t1 and g5733.t1, (Additional file 1) that together encode this enzyme complex in C. oleaginosus ATCC 20509. The overall process of fatty acid synthesis in C. oleaginosus ATCC 20509 (Fig. 1) can be simplified as follows:

$\mathrm{ATP}-$ citrate lyase $(\mathrm{ACL}):$ Citrate $+\mathrm{ATP} \rightarrow$ oxaloacetate + acetyl-CoA $+\mathrm{ADP}+\mathrm{P}_{i}$.

Acetyl-CoA Carboxylase (ACC) : acetyl-coA $+\mathrm{CO}_{2}+\mathrm{ATP} \rightarrow$ malonylCoA $+\mathrm{ADP}+\mathrm{P}_{i}$.

Fatty acid synthetase (FAS) : acetyl $-\mathrm{CoA}+7$ malonyl $-\mathrm{CoA}+14 \mathrm{NADPH}$

$+14 \mathrm{H}^{+} \rightarrow$ palmityl $-\mathrm{CoA}+14 \mathrm{NADP}^{+}+7 \mathrm{CoA}+7 \mathrm{CO}_{2}$.

Table 2 Genome annotation for Cutaneotrichosporon oleaginosus ATCC 20509

\begin{tabular}{ll}
\hline Annotation features & Results \\
\hline Genome size (Mbp) & 19.86 \\
No. of protein coding genes & 7861 \\
Protein length (median no. of amino acids) & 409 \\
Gene length (median bp) & 1708 \\
Transcript length (median bp) & 2460 \\
No. of genes with intron & 6891 \\
Proteins with at least one functional domain assigned & 5621 \\
No. of predicted (partial) EC's & 627 \\
No. of predicted (full) unique EC's & 1072 \\
Proteins with a predicted (full) EC's & 1778 \\
\hline
\end{tabular}

For the formation of unsaturated fatty acids (C16:1, C18:1, and C18:2) a fatty acid desaturase is required [33]. A single gene, g3345.t1, was predicted to encode this enzyme in C. oleaginosus ATCC 20509.

\section{Synthesis of triacylglyceride and phospholipids}

Like in other oleaginous yeast, the process of triacylglyceride (TAG) synthesis in C. oleaginosus ATCC 20509 starts with the formation of phosphatidic acid (PtdOH) from glycerol-3-phosphate either through the glycerol3-phosphate or the dihydroxyacetone phosphate pathway [31, 34] (Fig. 1). PtdOH is subsequently converted to diglyceride which later by addition of one acyl-CoA becomes triacylglyceride. 


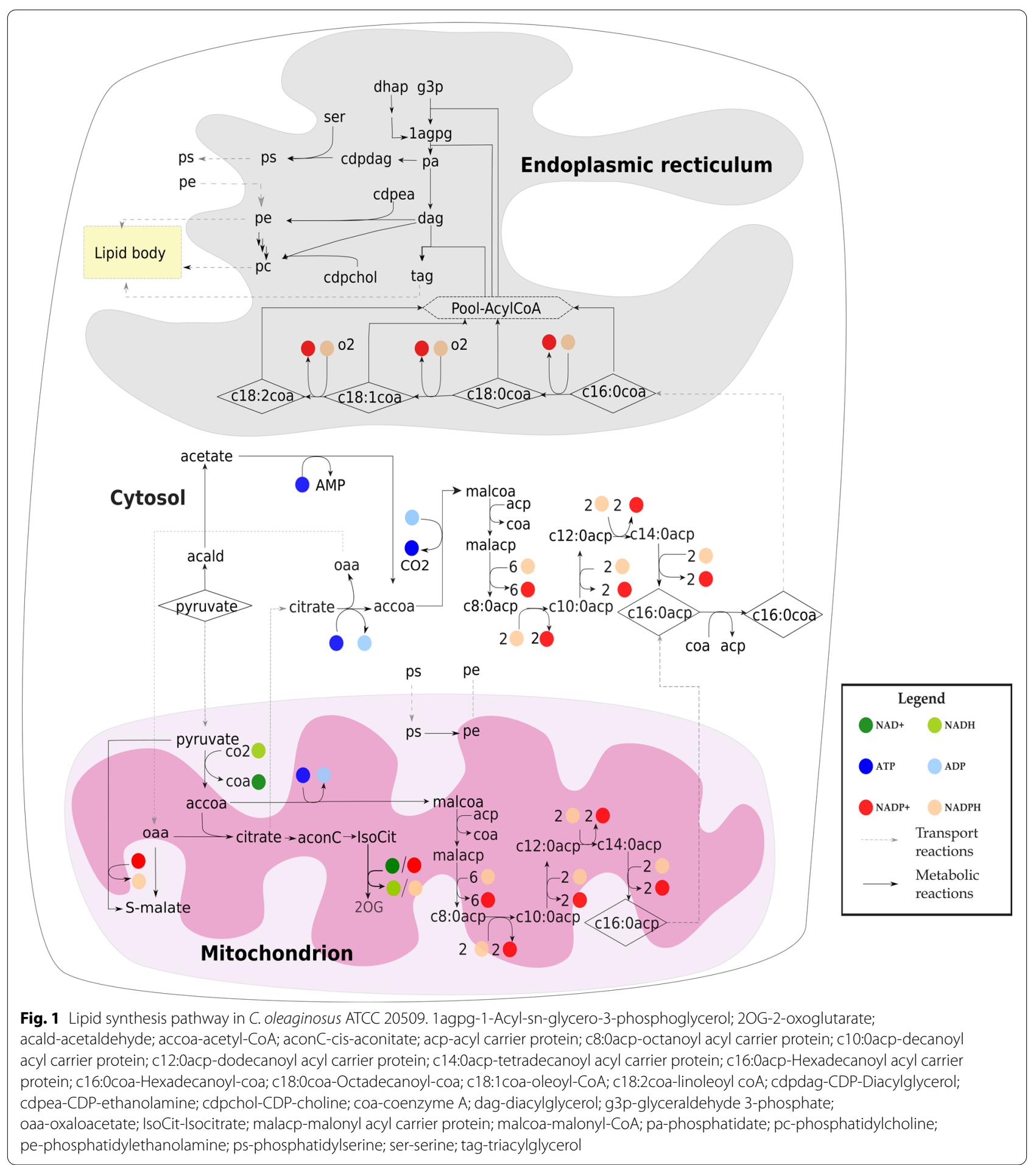

The main phospholipids in C. oleaginosus ATCC 20509 are phosphatidylcholine, phosphatidylethanolamine and phosphatidylserine [35]. They are synthesized from the
CDP-diacylglycerol (CDP-DAG) and the Kennedy (or CDP-choline) pathways [32, 36] (Fig. 1).

We provide more details of the reconstructed C. oleaginosus lipid synthesis pathway in Additional file 2. 
Table 3 Enzymes involved in lipid metabolism in Saccharomyces cerevisiae model, iNL800 [70], Yarrow lipolytica model, iNL895 [37] and Cutaneotrichosporon oleaginosus ATCC 20509 model, iNP636_Coleaginosus_ATCC20509 (this study)

\begin{tabular}{|c|c|c|c|c|}
\hline EC & Function & $\begin{array}{l}\text { S. cerevisiae } \\
\text { (iNL800) }\end{array}$ & $\begin{array}{l}\text { Y. lipolytica } \\
\text { (iNL895) }\end{array}$ & $\begin{array}{l}\text { C. oleaginosus } \\
\text { ATCC } 20509\end{array}$ \\
\hline EC 6.2.1.1 & Acetyl-coenzyme A synthetase 1 & Y & - & - \\
\hline EC 6.2.1.1 & Acetyl-coenzyme A synthetase 2 & Y & Y & Y \\
\hline EC 1.3.1.9 & Fatty acid synthase subunit beta & Y & $Y(2)$ & Y \\
\hline EC 2.3.1.86 & Fatty acid synthase subunit alpha & Y & $Y(2)$ & Y \\
\hline EC 2.7.7.41 & Phosphatidate cytidylyltransferase & Y & $Y(2)$ & Y \\
\hline EC 2.7.8.11 & CDP-diacylglycerol-inositol 3-phosphatidyltransferase & Y & Y & Y \\
\hline EC 2.7.8.8 & CDP-diacylglycerol-serine O-phosphatidyltransferase & Y & Y & Y \\
\hline EC 2.7.1.30 & Glycerol kinase & Y & Y & $Y(2)$ \\
\hline EC 1.1.1.8 & Glycerol-3-phosphate dehydrogenase (NAD(+)) & $Y(2)$ & Y & $Y(2)$ \\
\hline EC 2.3.1.51 & Probable 1-acyl-sn-glycerol-3-phosphate acyltransferase & Y & $Y(2)$ & Y \\
\hline EC 2.3.1.20 & Diacylglycerol O-acyltransferase & Y & Y & Y \\
\hline EC 2.3.1.158 & Phospholipid:diacylglycerol acyltransferase & Y & Y & Y \\
\hline EC 3.1.1.3 & Triacylglycerol lipase & $Y(3)$ & $Y(2)$ & $Y(2)$ \\
\hline EC 2.3.1.26 & Acyl-CoA:sterol acyltransferase & Y & Y & Y \\
\hline EC 1.14.19.1 & Acyl-CoA desaturase & Y & Y & Y \\
\hline EC 1.14.19.6 & $\Delta 12$ Fatty acid desaturase & - & Y & Y \\
\hline EC 1.3.3.6 & Acyl-coenzyme A oxidase & Y & $Y(3)$ & Y \\
\hline EC 2.3.1.16 & 3-ketoacyl-CoA thiolase, peroxisomal & Y & Y & $Y(2)$ \\
\hline EC 2.3.3.8 & ATP-citrate lyase, subunit a & - & Y & Y \\
\hline EC 2.3.3.8 & ATP-citrate lyase, subunit b & - & Y & Y \\
\hline EC 1.1.1.38 & NAD-dependent malic enzyme, mitochondrial & Y & Y & Y \\
\hline EC 6.4.1.2 & Acetyl-CoA carboxylase & Y & Y & Y \\
\hline
\end{tabular}

$\mathrm{Y}$ indicates the presence of the enzyme-encoding gene, $(-)$ indicates the absence of the enzyme-encoding gene. Number of isoenzymes is indicated in brackets

\section{Features of the model}

The GEM for $C$. oleaginosus was constructed using the well-curated GEM iNL895 [37] of the oleaginous model organism $Y$. lipolytica as a template. A template-based approach is often more efficient than starting from scratch however, as the use of a template could limit the scope of the specific GEM, an in-depth C. oleaginosus-specific curation of the here important target pathways, i.e. the fatty acid and lipid synthesis was performed. Of the 895 genes underlying the $Y$. lipolytica model, de novo genome annotation followed by manual curation led to the identification of 636 orthologs genes in C. oleaginosus ATCC 20509 that were used to generate the $i$ NP636_Coleaginosus_ ATCC20509 GEM. A full list of orthologs is provided in Additional file 3 . Both models cover the central carbon and lipid metabolism but, accounting for the differences in lipid and fatty acid profiles in these two organisms, in lipid formation there are differences in the number of isoenzymes involved. A comparison of enzymes involved lipid metabolism of C. oleaginosus ATCC20509, Y. lipolytica and the non-oleaginous model yeast, Saccharomyces cerevisiae is shown in Table 3.

Compared to $S$. cerevisiae there are few differences. $S$. cerevisiae lacks an ATP:citrate lyase and does not have

\begin{tabular}{|c|c|}
\hline Categories & Features \\
\hline Total reactions & 1553 \\
\hline Gene-associated reactions & $1142(84 \%)$ \\
\hline Exchange reactions & 189 \\
\hline Transport reactions & 486 \\
\hline Metabolic reactions & 878 \\
\hline Total metabolites & 1373 \\
\hline Unique metabolites & 786 \\
\hline Genes & 636 \\
\hline Compartments & 11 \\
\hline
\end{tabular}

Unique metabolites indicate species regardless of compartment

the gene encoding for a $\Delta 12$ fatty acid desaturase, which introduces the second double bond in the biosynthesis of 18:3 fatty acids. In S. cerevisiae, acetyl-CoA is produced from acetyl-coenzyme A synthetase encoded by two distinct genes ACS1 and ACS2 representing the "aerobic" and "anaerobic" forms of acetyl-coenzyme A synthetase, respectively [38]. In C. oleaginosus ATCC 20509 and $Y$. 


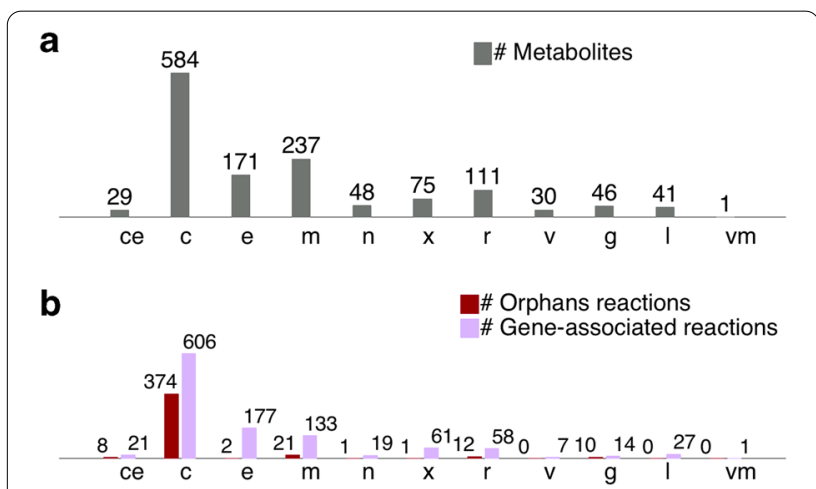

Fig. 2 Distribution of (a) metabolites and (b) reactions among compartments in iNP636_Coleaginosus_ATCC20509. Orphan reactions are exchange reactions, transport reactions, spontaneous reactions and reactions with no associated catalyzing genes. c-cytosol, ce-cell envelope, e-extracellular, g-Golgi, I-lipid particle, $m$-mitochondrion, $n$-nucleus, $r$-endoplasmic reticulum, $v$-vacuole, vm-vacuolar membrane, $x$-peroxisome

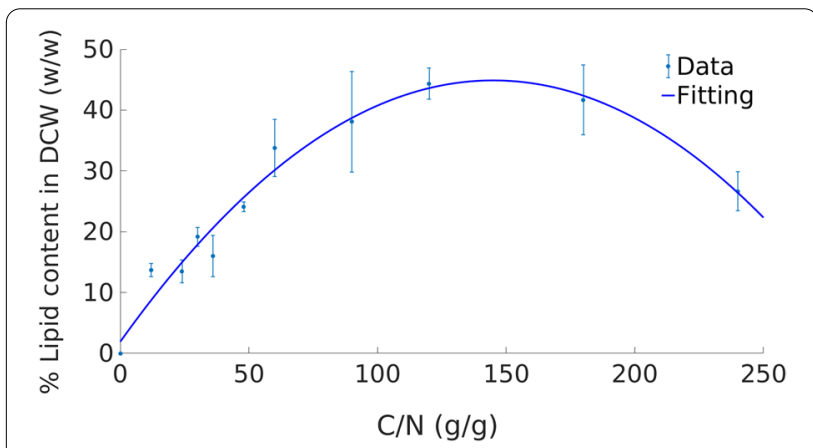

Fig. 3 Lipid content in C. oleaginosus ATCC 20509 dry cell weight (DCW) at different $\mathrm{C} / \mathrm{N}$ ratio. In vitro data were obtained from [25]. Fitting line corresponds to $y=-0.002^{*} x^{2}+0.59^{*} x+1.9$

lipolytica, there is only one acetyl-coA synthase gene, similar to ACS2 in S. cerevisiae.

After curation, the final GEM (iNP636_Coleaginosus_ ATCC20509) contains 1553 reactions, 1373 metabolites, 636 genes, and 11 compartments: cytoplasm, Golgi apparatus, cell envelope, endoplasmic reticulum, mitochondrion, nucleus, peroxisome, vacuolar membrane, vacuole, extracellular and lipid particle representing lipid droplets (Table 4 and Fig. 2).

\section{Biomass synthesis reaction}

The biomass synthesis reaction included in the model represents the formation of the main building blocks required for growth of the target organism [39, 40]. Application of growth-limiting nutrients however, may induce large variations in biomass composition. Model flux distributions can be very sensitive to such changes, compromising the predictive accuracy of the metabolic model [40].

The biomass composition of C. oleaginosus ATCC 20509 was shown to vary along with the $\mathrm{C} / \mathrm{N}$ ratio in the medium $[8,25,41]$, as in nitrogen-limiting conditions excess carbon is converted to lipids.

Experimental data show an increase in lipid content with increasing $\mathrm{C} / \mathrm{N}$ ratio [25] until a maximum is observed at $\mathrm{C} / \mathrm{N}$ ratio of $120 \mathrm{~g} / \mathrm{g}$ (Fig. 3). The link between lipid content and $\mathrm{C} / \mathrm{N}$ ratio can be approximated by a quadratic relationship, as shown in Fig. 3. In addition to lipids, the biomass content of protein and carbohydrate also varies with the $\mathrm{C} / \mathrm{N}$ ratio [41]. Here, we model weight fraction of biomass that corresponds to carbohydrates (given by $w_{C}$ ), proteins $\left(w_{P}\right)$ and total lipids $\left(w_{T L}\right)$ in the biomass using: $w_{C}+w_{P}+w_{T L}=0.95$ biomass. The remaining $5 \%$ of the biomass weight is assigned to RNA, DNA, minerals and cofactor content. As these represent minor quantities in the biomass, their coefficients are assumed to be constant.

Upon nitrogen starvation, the yeast cells start accumulating intracellular sugars [41] as short-term energy storage [11, 42]. These intracellular sugars will be then converted to long-term energy storage in form of lipid droplet [41]. Furthermore, nitrogen depletion leads to a decrease in protein content as proteins are used as nitrogen source. No changes in carbohydrate profile in the cell wall under nutrient shortage conditions has been reported [11]. Therefore, we assume that nitrogen depletion will lead to a maximum carbohydrate content in the cell and that the excess carbon will be rerouted for lipid synthesis. Data from [8] at a relatively low $\mathrm{C} / \mathrm{N}$ ratio (2.8) suggest $11 \%$ as a reasonable and conservative estimate for this weight fraction. Combining this expression and the relationship in Fig. 3a biomass synthesis reaction for nitrogen starvation can be dynamically built for any $\mathrm{C} / \mathrm{N}$ ratio (Additional file 4).

The amount of lipids in the biomass reaction varies along with the $\mathrm{C} / \mathrm{N}$ ratio, however the lipid composition does not change. TAGs still make up $90 \%$ of total lipid in C. oleaginosus ATCC 20509 [4] and phospholipids for the remaining $10 \%$ [4]. The phospholipids, phosphatidylserine, phosphatidylethanolamine and phosphatidylcholine are added with equal weights. Finally, the fatty acid content of lipids (25\% hexadecanoic (C16:0), 10\% octadecanoic acid (C18:0), 57\% oleic acid (C18:1), and 7\% linoleic acid $(\mathrm{C} 18: 2)[4,5])$ were also considered to be stable.

\section{Lipid production and growth in C. oleaginosus ATCC 20509 Effect of the $\mathrm{C} / \mathrm{N}$ ratio on lipid production}

We compared simulation results from our model, $i$ NP636_Coleaginosus_ATCC20509, with simulations obtained from the response surface method [25] using 
a

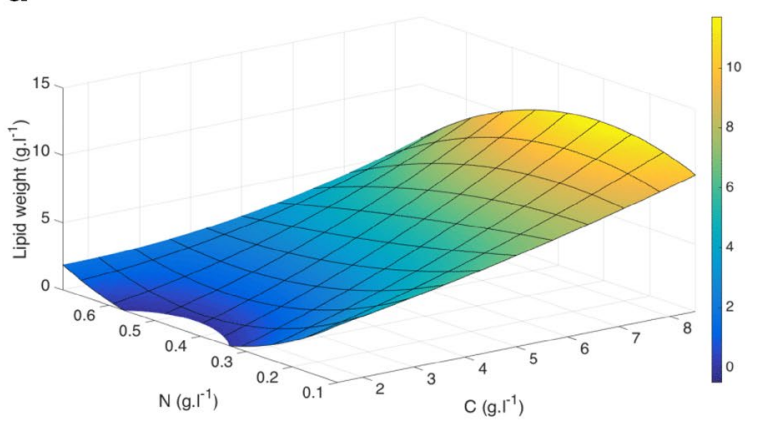

C

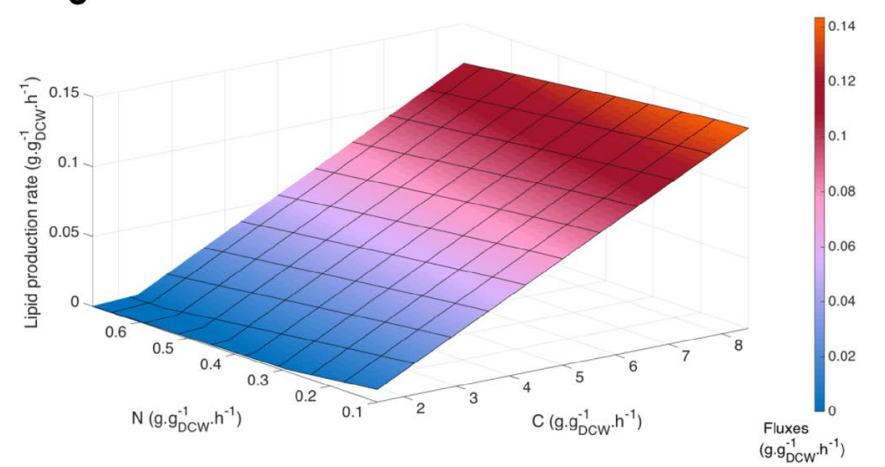

b

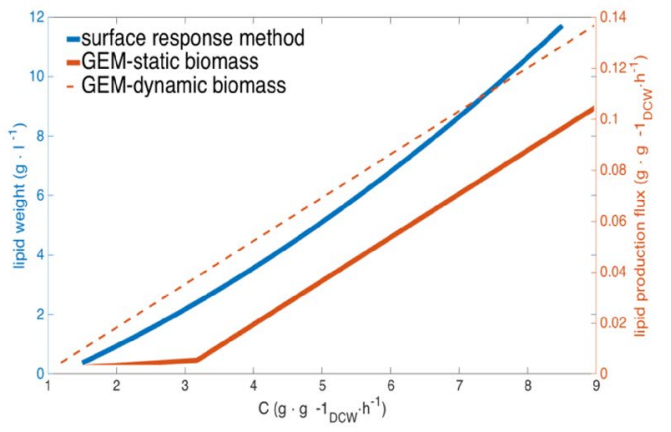

d

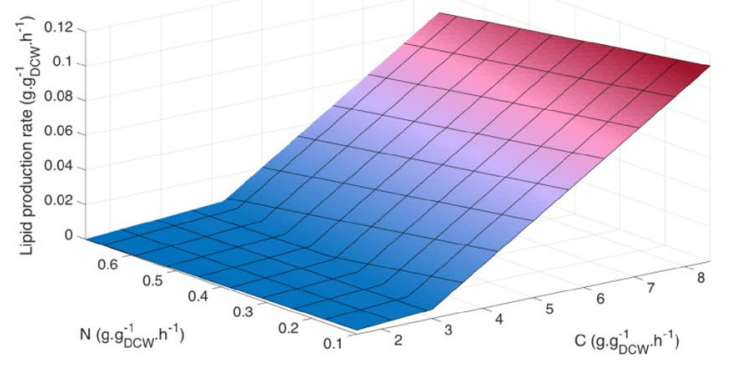

Fig. 4 Simulations of impact of C/N ratio on lipid production by C. oleaginosus ATCC 20509. a: Simulation using the surface response model [25], b: A comparison of lipid production at a fixed N concentration at 0.3 (g/l) between surface response method in [25] and iNP636_Coleaginosus_ ATCC20509 using a standard biomass (static) and condition-specific (dynamic) biomass. c: iNP636_Coleaginosus_ATCC20509 simulation using the proposed condition-specific biomass objective function, d: iNP636_Coleaginosus_ATCC20509 simulation using a standard biomass objective function. Glucose is used as a carbon source as was used in the response method in [25]

either a fixed standard or a condition specific biomass objective function. The results are presented in Fig. 4.

When the condition-specific biomass objective function is applied (Fig. 4b) GEM predictions are better aligned with predictions obtained with the response surface method in [25] (Fig. 4a) underpinning the crucial role of high $\mathrm{C} / \mathrm{N}$ ratios in lipid production.

\section{Effect of the carbon source on lipid production and growth} Carbon sources have been shown to have different effects on growth and lipid production in oleaginous yeast $[1,8]$. C. oleaginosus ATCC 20509 is able to grow on glycerol, sucrose, glucose, fructose, ethanol or xylose as sole carbon source $[11,25]$ and in silico growth was evaluated on these sources (Fig. 5).

Overall, except for ethanol growth was predicted in all tested carbon sources. In our in silico experiment, uptake rates were adjusted for each carbon source to guarantee the same C-mol was provided. On all tested carbon sources the model predicted favorable growth in nutrient-rich conditions. Comparable growth rates were obtained in sucrose, glucose, fructose and xylose (Fig. 5).
A lower growth rate was obtained for glycerol while no growth was obtained when ethanol was used as sole carbon source.

Effects of 5-carbon sugars, i.e. xylose, 6-carbon sugars, i.e. glucose and fructose, and of sucrose on growth in $C$. oleaginosus ATCC 20509 have been studied extensively, and results vary among these studies. According to [25], comparing fructose, glucose, xylose and sucrose, C. oleaginosus ATCC 20509 grows the fastest in fructose, the slowest in sucrose while there is no significant difference between glucose or xylose. According to [26], xylose is favored over glucose for biomass generation. These differences can be due to various factors such as $\mathrm{pH}$, temperature, oxygen, dilution rate, and fermentation modes across experiments. When growing in different fermentation modes, i.e. batch, fed batch, and continuous fermentation, the microorganisms are subjected to differences in environment, substrate availability and by-product concentration [43]. In addition, different carbon sources may have different uptake rates. These factors can result in different growth rates, biomass and by-product accumulation. In this study, we simulated the process in 


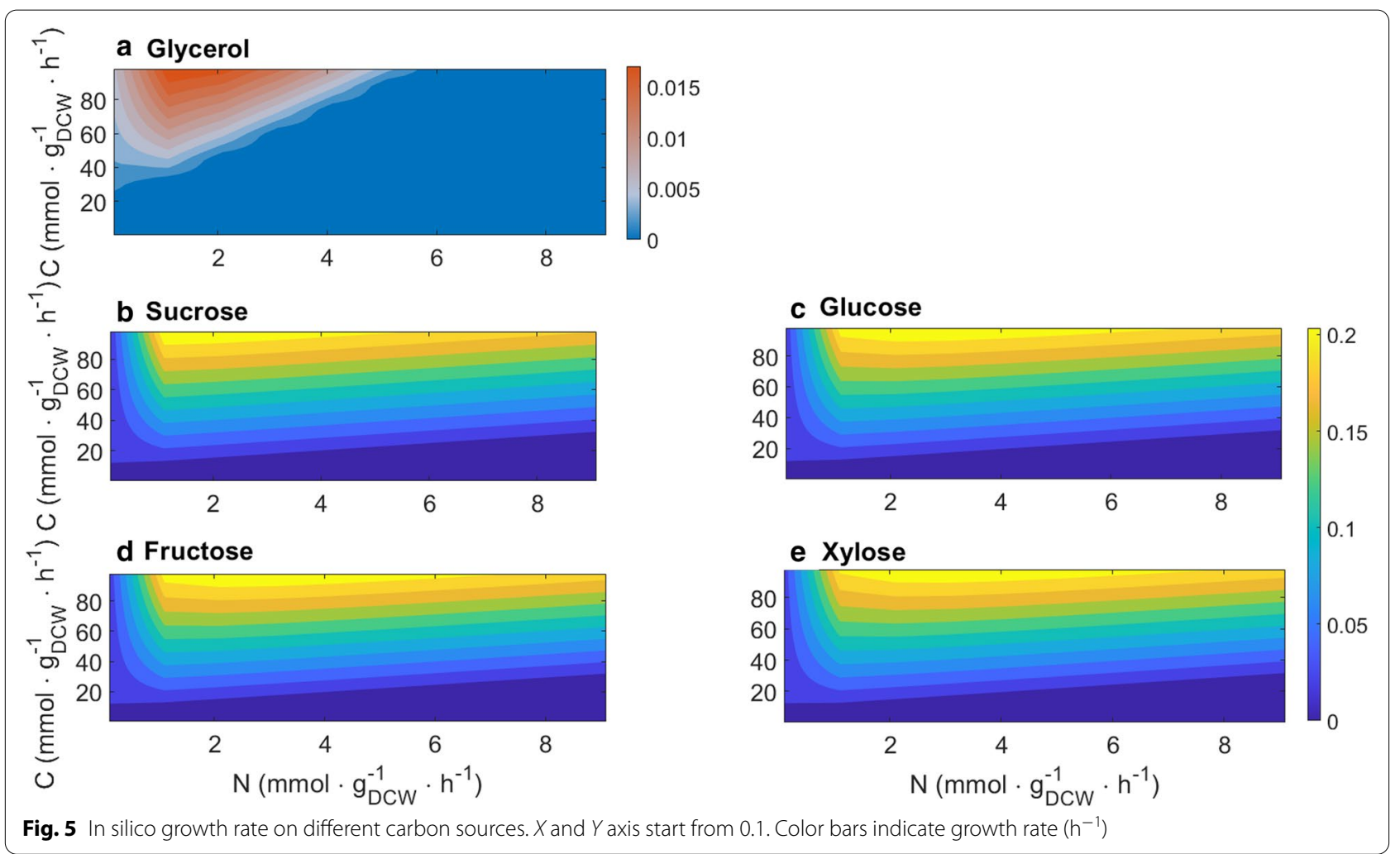

continuous fermentation and assumed the same uptake rate for all carbon sources.

As for growth, a similar trend was predicted for lipid production on different carbon sources (Fig. 6). For all tested carbon sources, the model predicted highest lipid production at high $\mathrm{C} / \mathrm{N}$ ratios. Model prediction for lipid production in glycerol is noticeably different from that of other carbon sources. This is consistent with findings in [44] who reported a maximum growth rate and lipid production of C. oleaginosus ATCC 20509 on glycerol in a fed-batch fermentation mode at $16 \mathrm{~g} / \mathrm{l}$ glycerol and $0.27 \mathrm{~g} / \mathrm{l} \mathrm{NH} \mathrm{NH}_{4} \mathrm{Cl}$, corresponding to a $\mathrm{C} / \mathrm{N}$ ratio of $100 \mathrm{~mol} /$ mol.

The model predicted the highest lipid production rate in sucrose, glucose, fructose, and xylose. Glycerol yielded lower lipid production rate. Similar to growth, literature also captured contrasting findings on lipid production on different carbon sources. Across various carbon sources, xylose was found the most suitable sugar source for lipid yield in batch and chemostat cultures [22]. On the other hand, a lower lipid production on xylose compared to glucose were reported in other studies [25, 45]. This disagreement between studies can be due to influence of other factors such as temperature, oxygen and fermentation mode [11].

\section{Acetyl-CoA source for lipid production in C. oleaginosus ATCC 20509}

Lipid synthesis requires a constant supplement of fatty acid and fatty acid synthesis in turn requires a continuous supplement of acetyl-CoA [32]. In non-oleaginous yeast such as S. cerevisiae, the main source of acetyl-CoA is the ligation of acetate and coenzyme A by acetyl-coA synthase [32]. Oleaginous yeast such as $Y$. lipolytica, do not have the gene encoding for acetyl-CoA synthase [32].

The main source for acetyl-CoA in oleaginous yeasts is believed to be the cleavage of citrate to release acetyl$\mathrm{CoA}$ and oxaloacetate in the cytosol by ATP:citrate lyase [32]. This implies that there is a continuous export of citrate from the mitochondria to the cytosol. Our model, under assumed chemostat cultivation conditions, also predicts this. The flux of the citrate transport reaction increases positively with ATP:citrate lyase whose flux also increases sharply after passing $\mathrm{C} / \mathrm{N}$ ratio of $10 \mathrm{~g} / \mathrm{g}$ (Fig. 7). Fluxes through acetyl-coA pool and lipid synthesis reaction also surged after passing the same $\mathrm{C} / \mathrm{N}$ ratio (Fig. 7). The large standard deviations in Fig. 7 represent alternative flux distributions that are compatible with the set constraints. This variability reflects both the metabolic flexibility of this organism and the lack of sufficient data to fully constrain the model, a common problem in GEM model analysis. 

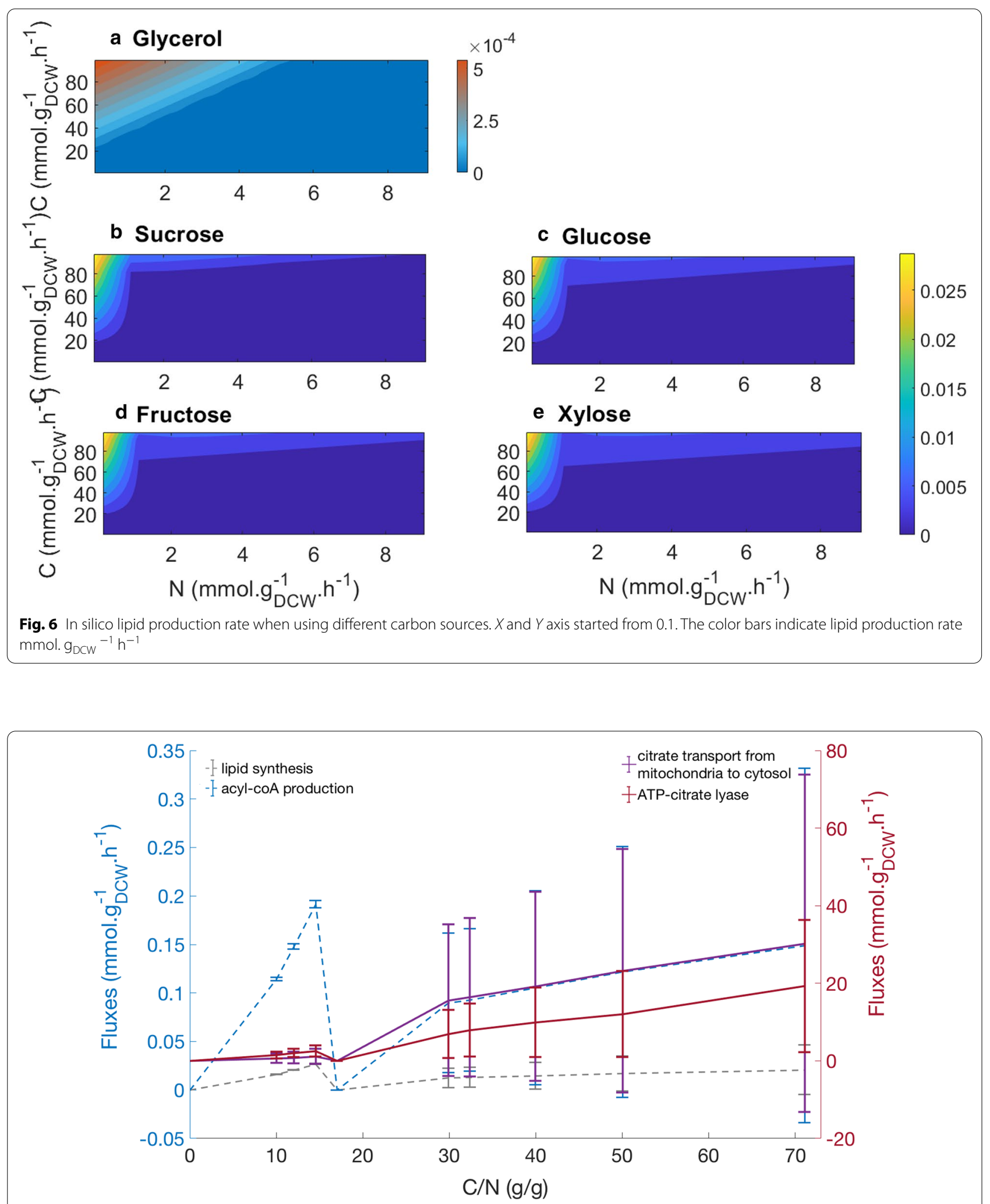

Fig. 7 In silico flux analysis of acetyl-CoA source for lipid synthesis. The citrate transport from mitochondria to cytosol and ATP-citrate lyase which catalyzes the reaction ATP + citrate + Coenzyme-A acetyl-CoA + oxaloacetate $+P_{\mathrm{i}}+\mathrm{ADP}$ in cytosol follow the red Y-scale; acyl-coA production (an artificial reaction represents acyl-coA Pool in the model); and lipid synthesis (an exchange reaction of lipid) follow the blue Y-scale. Bars indicate the standard errors of means of fluxes through each reaction. The $\mathrm{C} / \mathrm{N}(\mathrm{g} / \mathrm{g})$ refers to the ratio between the uptake rates of carbon and nitrogen sources 
As reported in [46], after passing the critical $\mathrm{C} / \mathrm{N}$ of $11 \mathrm{~g} / \mathrm{g}$, when the nitrogen concentration is limiting further growth, the yeast starts to accumulate more lipids. In order to sustain cellular functioning, the cell degrades AMP to inosine monophosphate and ammonium ions [3, 32]. A decreased AMP concentration in turn down-regulates the activity of isocitrate dehydrogenase $[3,32,47$, 48]. This enzyme converts citrate to isocitrate. Its downregulation, therefore, leads to the accumulation of citrate in mitochondria. Accumulated citrate is then exported to cytosol where it is hydrolysed to acetyl-CoA and oxaloacetate by ATP:citrate lyase [3, 32]. This process provides more acetyl-CoA for fatty acid synthesis which further enhances lipid production in the cell [3]. Although FBA analysis does not account for regulation, the same trend was observed in our simulations, that clearly indicate the association between increased flux through ATP:citrate lyase reaction and lipid production (Fig. 7). Furthermore, model simulations show no alternative lipid production pathway as in silico growth is inhibited when simulating a knock out of this enzyme. Our model suggests the ATP-citrate lyase reaction as the main source for acetylCoA suggesting that overexpression of ATP-citrate lyase enzyme could help to further improve lipid production.
This strategy has been successfully implemented in $Y$. lipolytica [49].

\section{Lipid metabolism regulation}

The effect of nitrogen limitation on lipid production was studied by analyzing the effect of the $\mathrm{C} / \mathrm{N}$ ratio on (i) the in silico flux distribution and (ii) the transcriptional landscape of C. oleaginosus ATCC 20509 grown on glycerol.

i. In silico flux distribution: We tested lipid production at different $\mathrm{C} / \mathrm{N}$ ratios while keeping the carbon concentration constant at either 16,24 or $32 \mathrm{~g} / \mathrm{g}$ DCW (Fig. 8) as for the same $\mathrm{C} / \mathrm{N}$ ratio the absolute amount of carbon supplied has been shown to greatly affect lipid production [8]. The model predicted that for the higher $\mathrm{C} / \mathrm{N}$ ratios, more carbon is required to sustain lipid production. With $16 \mathrm{~g} / \mathrm{g} \mathrm{DCW}$ carbon no lipid could be produced at a $\mathrm{C} / \mathrm{N}$ ratio of 240 (g/g). Likewise, with $24 \mathrm{~g}$ carbon, no lipid formation was predicted at a $\mathrm{C} / \mathrm{N}$ ratio of $300(\mathrm{~g} / \mathrm{g})$. Only with $32 \mathrm{~g} / \mathrm{g}$ DCW carbon, lipid accumulated at the complete range of $\mathrm{C} / \mathrm{N}$ ratio's tested.

For the three tested carbon concentrations, the same trends in flux distribution were obtained (Fig. 8). When

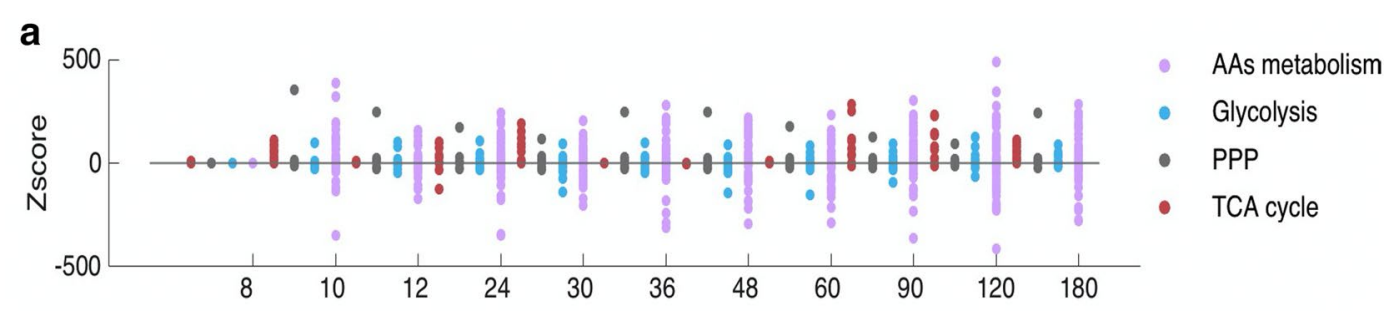

b
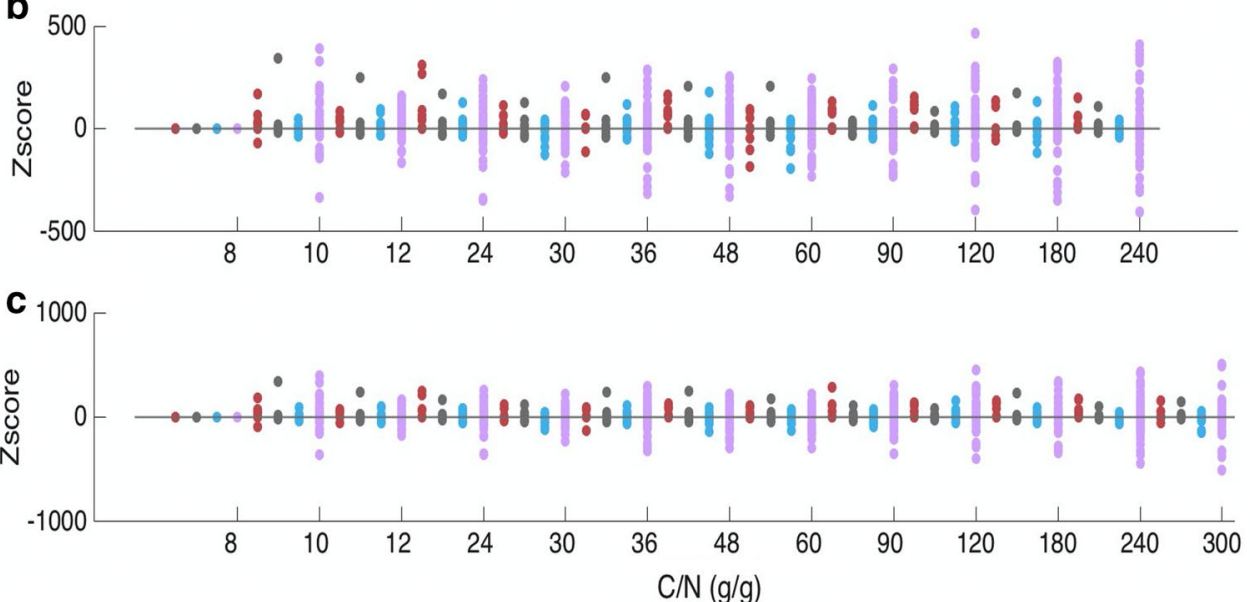

Fig. 8 In silico flux changes in C. oleaginosus ATCC 20509 at different C/N ratio with a $16 \mathrm{~g}$ carbon; b $24 \mathrm{~g}$ carbon; c $32 \mathrm{~g}$ carbon using glycerol as a sole carbon source. A C/N ratio of $6 \mathrm{~g} / \mathrm{g}$ was used as reference point to calculate $Z$-score for each $\mathrm{C} / \mathrm{N}$ ratio. The $\mathrm{C} / \mathrm{N}(\mathrm{g} / \mathrm{g}$ ) refers to the ratio between the uptake rates of carbon and nitrogen source. $Z$-score $>0$ indicates an increase in flux compare to that at reference point; $Z$-score $<0$ indicates a decrease in flux compared to that at reference point. PPP-pentose phosphate pathway; AAs metabolism-amino acids metabolism. Each dot in the graph represents a reaction in the corresponding pathway 
increasing the $\mathrm{C} / \mathrm{N}$ ratio, a majority of reactions in TCA and PPP have their fluxes increased. This could be due to the high demand of reducing power, i.e. NADPH, of lipid production. Fluxes through glycolysis are greatly diverse when changing the glycerol concentration. Reactions related to glucose catabolism such as hexokinase (D-glucose:ATP) and glucose-6-phosphate isomerase (PGI) have their fluxes reduced. Down regulation of PGI was reported to lead to the accumulation of intracellular sugar which is later converted to lipid in the nitrogendepletion stage [41]. Downstream reactions in glycolysis such as 6-phosphofructo2-kinase, pyruvate kinase and acetyl-CoA synthetase have their fluxes increased. Upregulation of these enzymes can be a result from a high demand of precursors for lipid accumulation.

As already mentioned in [50] we also observed flux fluctuations in amino acid metabolism (Fig. 8). Fluxes through enzymes in amino acid degradation pathways, i.e. argininosuccinate lyase, L-hydroxyproline dehydrogenase (NAD), and L-glutamate 5-semialdehyde dehydratase increase at a high $\mathrm{C} / \mathrm{N}$ ratio. This is expected since upon nitrogen limitation, amino acid degradation provides an alternative nitrogen source. Reactions in amino acids synthesis such as glutamine synthetase and ornithine decarboxylase, on the other hand, had their fluxes reduced.

ii. Nitrogen limitation induced transcriptional changes: RNAseq data were obtained from C. oleaginosus ATCC 20509 when growing in a glycerol medium with an initial $\mathrm{C} / \mathrm{N}(\mathrm{g} / \mathrm{g})$ ratio of 28 and 2.8 , respectively. At the time of sampling, nitrogen was significantly depleted when the high $\mathrm{C} / \mathrm{N}$ ratio was used (Table 5). There were 7272 genes expressed in high $\mathrm{C} / \mathrm{N}$ ratio medium and 7246 genes expressed in low $\mathrm{C} / \mathrm{N}$ ratio medium $(>50$ Counts Per Million). When comparing low $\mathrm{C} / \mathrm{N}$ ratio to high $\mathrm{C} / \mathrm{N}$ ratio medium, 75 genes were found to be up-regulated and 26 were down-regulated (see Additional file 5). Interestingly, the majority of these genes code for unknown protein functions. No genes involved in primary metabo- lism were found to have significant different expression level in either low or high $\mathrm{C} / \mathrm{N}$ ratio.

In response to nitrogen starvation the gene expression levels of many genes in the lipid synthesis pathway were reported to fluctuate in Y. lipolytica [51], in contrast Kerhoven et al. [50] reported no significant change in transcription level of these genes under nitrogen limitation. Using xylose as carbon source the Acetyl-CoA carboxylase (ACC) gene was found to be upregulated in Trichosporon oleaginosus strain IBC0246 under nitrogen limitation [52] and the same authors also reported significant upregulation of fatty acid synthetase (FAS1 and FAS2), malic enzyme and ATP-citrate lyase (ACL) under these conditions.

In our case, upon growth in glycerol, RNAseq analysis showed no difference in transcription level of genes involved in lipid synthesis pathway in C. oleaginosus ATCC 20509. The model however, was able to predict lipid production at different $\mathrm{C} / \mathrm{N}$ ratio qualitatively consistent with experimental data. This suggests that in glycerol C. oleaginosus ATCC 20509 lipid metabolism is not regulated at the transcriptional level. Pathway flux is controlled by simultaneous multisite modulation through action on a number of enzymes [53]. This suggests that other regulatory effects, such as regulation of translation or allosteric effects may dominate in C. oleaginosus. In Lipomyees starkeyi, an oleaginous yeast, and Aspergillus niger, a citric producing yeast, ATP:citrate lyase, the key enzyme in lipid synthesis is controlled by the energy charge and fatty acid acyl CoA esters [54]. While human ATP:citrate lyase activity has been reported to be regulated by in vitro allosteric effects via phosphorylation [55]. Little is know on the regulation of this enzyme in $C$. oleaginosus.

\section{Conclusions}

In this study, we introduced the first GEM for C. oleaginosus ATCC 20509 and as such iNP636_Coleaginosus ATCC20509 represents a valuable platform to integrate, interpret and combine many decades of experimental efforts since its first isolation from a dairy farm in 1978

Table 5 Glycerol and NH4CI levels obtained from HPLC analysis and NH4 chemical analysis

\begin{tabular}{|c|c|c|c|c|c|c|c|c|}
\hline & \multicolumn{2}{|l|}{ OD 650} & \multicolumn{2}{|c|}{ glycerol (g/L) } & \multicolumn{2}{|c|}{$\mathrm{NH} 4 \mathrm{Cl}(\mathrm{g} / \mathrm{L})$} & \multirow{2}{*}{$\begin{array}{l}\mathrm{C} / \mathrm{N}(\mathrm{mol} / \mathrm{mol}) \\
T=18 \mathrm{~h}\end{array}$} & \multirow{2}{*}{$\begin{array}{l}\mathrm{CDW}^{\mathrm{a}} \\
(\mathrm{mg} / \\
50 \mathrm{ml})\end{array}$} \\
\hline & $T=0 \mathrm{~h}$ & $T=18 \mathrm{~h}$ & $T=0 \mathrm{~h}$ & $T=18 \mathrm{~h}$ & $T=0 \mathrm{~h}$ & $T=18 \mathrm{~h}$ & & \\
\hline A1 & 2.75 & 12.2 & 20.5 & 11.3 & 1.1 & 0.022 & 896 & 404 \\
\hline A2 & 2.9 & 11.8 & 20.5 & 11.4 & 1.1 & 0.015 & 1325 & 365 \\
\hline B1 & 2.8 & 10.4 & 10.2 & 1.6 & 4.7 & 2.9 & 0.96 & 445 \\
\hline B2 & 2.85 & 10.4 & 10.2 & 2.5 & 4.7 & 3.6 & 1.2 & 445 \\
\hline
\end{tabular}

${ }^{a}$ Cell dry weight 
$[13,56]$. The model gave qualitative predictions at different $\mathrm{C}$ sources consistent with experimental data, highlighted the lipid production lifestyle of $C$. oleaginosus ATCC 20509 and pinpointed ATP-citrate lyase as a target to further improve lipid production. Analysis of RNAseq revealed that lipid production in C. oleaginosus ATCC 20509 in glycerol does not appear to be regulated at the transcriptional level.

C. oleaginosus is known to have a great potential for lipid production due to its efficient growth on inexpensive carbon sources such as glycerol. Our simulations show that its potential has not yet been fully explored and can be optimized further. The predictive accuracy of $i$ NP636_Coleaginosus_ATCC20509 renders its great potential for future studies to guide metabolic engineering for the production of high-value industrial compounds such as polyunsaturated plant-like fatty acids.

\section{Materials and methods}

\section{C. oleaginosus ATCC 20509 experimental data collection}

The strain was cultivated in the same basal medium as described in [8] except for the glycerol and $\mathrm{NH}_{4} \mathrm{Cl}$ concentration which was adapted in order to achieve the chosen $\mathrm{C} / \mathrm{N}$ ratio. A C/N ratio of 28 was obtained by adding $16 \mathrm{~g} / \mathrm{l}$ glycerol and $1 \mathrm{~g} / \mathrm{l} \mathrm{NH} \mathrm{N}_{4} \mathrm{Cl}$ (medium $\mathrm{A}$ ), while in other sample, $8 \mathrm{~g} / \mathrm{l}$ glycerol and $5 \mathrm{~g} / \mathrm{l} \mathrm{NH} \mathrm{N}_{4} \mathrm{Cl}$ was added to make a $\mathrm{C} / \mathrm{N}$ ratio of 2.8 (medium $\mathrm{B}$ ). The $\mathrm{C} / \mathrm{N}$ ratios were taken from [8], which shows C. oleaginosus grows at a $\mathrm{C} / \mathrm{N}$ ratio of less than 5 , and lipid production for a ratio between 20 and 40 carbon / nitrogen.

Two biological replicates for each condition were inoculated from a freshly prepared YPD-agar plate in $50 \mathrm{ml}$ of YPD medium and grown $\mathrm{O} / \mathrm{N}$ in a $100-\mathrm{ml}$ Erlemeyer flask at $30{ }^{\circ} \mathrm{C}$ and $225 \mathrm{rpm}$. The culture was divided in two $25 \mathrm{ml}$ portions and centrifuged (10 $\mathrm{min} .300 \mathrm{rpm}$ ) to collect the cells. The cell pellets were resuspended in $30 \mathrm{ml}$ medium A or medium B. $4 \mathrm{ml}$ of the resuspended cells was used to start duplicate cultures in medium $\mathrm{A}$ and $\mathrm{B}$ which were incubated for $18 \mathrm{~h}$ at $30{ }^{\circ} \mathrm{C}$ and $225 \mathrm{rpm}$. Each culture was divided in two equal portions and the cells were harvested by centrifugation and the wet pellet frozen in liquid and used for RNA extraction.

We measured the concentration of glycerol and $\mathrm{NH}_{4} \mathrm{Cl}$ in the medium at the initial condition and at the sampling point (Table 5). Glycerol and $\mathrm{NH}_{4} \mathrm{Cl}$ were measured with HPLC analysis and NH4 chemical analysis, respectively.

\section{RNA extraction procedure}

RNA was extracted using an acidic hot phenol extraction procedure. Briefly, the cell pellet was ground in liquid nitrogen and mixed with 4 volumes of pre-warmed $\left(60{ }^{\circ} \mathrm{C}\right)$ phenol+extraction buffer (1\% SDS, $10 \mathrm{mM}$ EDTA, $0,2 \mathrm{M} \mathrm{NaAc}(\mathrm{pH}$ 5)) after this 2 volumes of chloroform were added and mixed thoroughly. After centrifugation the buffer layer was washed once with chloroform. RNA was precipitated from the buffer layer by adding $8 \mathrm{M} \mathrm{LiCl}$ to and end concentration of $2 \mathrm{M}$. After centrifugation the pellet was washed once with $2 \mathrm{M} \mathrm{LiCl}$ and twice with $70 \%$ ethanol. The remaining pellet was resuspended in RNase-free water. Total RNA extract, RNA sequencing, and RNAseq data processing were performed as described in [8]. Samples were sequenced by NovoGene using Total RNA.

\section{RNAseq analysis}

Raw read counts in two C/N ratios, 2.8 and 28 (mol C/ mol N), were obtained with the RNA-seq aligner STAR (v2.6.0b) [57] using the parameter "-quantMode GeneCounts", the public genome sequence MATS00000000.1 of C. oleaginosus ATCC 20509 and the GTF file obtained from BRAKER1. Read count data were then analyzed using DESeq2 [58] to identify genes that have different expression when changing the $\mathrm{C} / \mathrm{N}$ ratio. Two biological replicates for each condition were provided. The statistical significance of gene expression differences was evaluated using a false discovery rate $(\mathrm{FDR})<0.05$ and $\mid \log _{2}$ (fold change) $\mid \geq \log _{2} 1.5$ as a threshold.

\section{Genome sequence}

The genome sequence MATS00000000.1 from Cutaneotrichosporon oleaginosus ATCC 20509 reported by [28] was annotated and used to build the model. The genome sequence has $19.86 \mathrm{Mbp}$ and a GC content of $60.7 \%$.

\section{Genome annotation}

Unsupervised RNA-Seq-based gene prediction of C. oleaginosus ATCC 20509 was performed with BRAKER1 v1.10 [29] in combination with HISAT2 (v2.1.0) [59] using all the RNAseq datasets combined.

The genome, predicted gene structures and their proteins sequences were directly stored in the SAPP semantic (RDF) database [60] using the GBOL ontology [61]. Protein signature prediction was done with a standalone version of InterProScan v5.24.64.0 [62] using the default databases. EnzDP [63] was used to assign EC numbers to Proteins. This is with a confidence score cut-off of 0.2. Both tools were used in direct interaction with the previously mentioned SAPP database. Construction of iNP636_Coleaginosus_ATCC20509 model.

\section{Software environment}

The model was read, modified and analyzed in MATLAB (version R2015b) [64], using COBRA toolbox 3.0 [65] and GLPK [66] as a linear solver. 


\section{Construction of the draft model}

A draft model was constructed using the scaffold-based method described in [37]. A GEM of Y. lipolytica, considered as a model for oleaginous organism [2,32] was chosen as a reference scaffold. There are 5 published models for Y. lipolytica iNL895 [37], iYL619 [67], iMK735 [68], iYALI4 [50], iYLI647 [69]. Y. lipolytica iNL895 model [37] was used as a scaffold because it contains the most reactions and genes and was also constructed based on the $S$. cerevisiae model, iIN800 [70] which was specialized for lipid synthesis.

To find ortholog proteins from Y. lipolytica to C. oleaginosus ATCC 20509, the enzyme-coding-genes obtained from Y. lipolytica iNL895 model were functionally annotated in the same manner as C. oleaginosus ATCC 20509 and stored in the SAPP database. A combination of the protein signatures, EC prediction, BLAST and manual curation was used to find the orthologues.

If an ortholog gene was found in C. oleaginosus ATCC20509, the associate reaction in the scaffold iNL895 was kept. In addition, exchange and non-enzymatic transport reactions for the medium were kept. Spontaneous and growth essential orphan reactions from the scaffold were also preserved. This step resulted in a draft model for further curation.

\section{Curation of the draft model}

In order to build a working GEM the draft model expanded and refined in the following manner:

i. The lipid synthesis pathway was curated based on KEGG [71], literature [3-5, 32] as well as experimental data in $[8,44]$.

ii. The central metabolic network, including glycolysis, pentose phosphate pathway and TCA cycle were manually curated based on literature [72, 73].

iii. Growth-associated maintenance energy (GAM) was adopted from $Y$. lipolytica model, iNL895. Non-growth associated maintenance energy in $C$. oleaginosus ATCC 20509 is known to be relatively low in comparison with other yeasts [8], in the model this value was set as $1 \mathrm{mmol} \cdot g D C W-1$. $h-1$.

iv. The draft model was further curated by removing gaps, irrelevant reactions and infeasible energy production cycles. Method described in [74] was employed to identify infeasible energy production cycles in our model. In short, we added energy dissipation reactions for ATP, CTP, GTP, UTP, $\mathrm{NADH}, \mathrm{NADPH}, \mathrm{FADH} 2$ and proton with unconstrained bounds. Fluxes through all network reactions, except the added energy dissipation reactions were constrained to range $[-1,1]$ for reversible and
$[0,1]$ for irreversible reactions. No uptake nutrients were allowed. Each energy dissipation reaction was maximized to identify the presence of infeasible loops.

\section{Development of a condition-specific biomass function}

The four major macro-molecules of living cells are proteins, carbohydrates, nucleic acids and lipids [75]. The ratio between them are assumed to be different in different conditions. We assumed lipid, protein and carbohydrate makeup $95 \%$ of the cell dry weight. Depending on the $\mathrm{C} / \mathrm{N}$ ratio in the medium, the ratio between them will vary. Nucleic acids and other cofactors and mineral only make up a small fraction of the biomass, and kept constant. Using data from literature, we parametrized the relationship between the biomass and carbohydrates, proteins and lipids under nitrogen starvation using:

$$
\begin{aligned}
& \text { 0.11biomassCarbohydrate }+ \text { biomassProtein } \\
& + \text { biomasstotalLipid }+0.05 \text { biomassother }=\text { biomass }
\end{aligned}
$$

This assumes that under nitrogen starvation, $11 \%$ of the cellular biomass corresponds to carbohydrates, $5 \%$ to nucleic acids and other components and the remaining fraction correspond to proteins and total lipids. We used the experimental data in [25] to model the $\mathrm{C} / \mathrm{N}$ ratio in the media and lipid accumulation using a quadratic regression (Fig. 3) with a correlation coefficient of 0.98. This enables the estimation of the contribution of lipids $w_{T L}$ to the biomass. For this, $\mathrm{C}$ and $\mathrm{N}$ uptake rates were used to compute the ratio between both components as we assumed a simulation scenario (chemostat) where no net accumulation of either one happens. Using this approach, we can generate specific biomass reaction at any $\mathrm{C} / \mathrm{N}$ ratio using carbon source and nitrogen source uptake rates as the sole inputs. Details regarding components and their coefficients in the biomass reaction at normal condition, i.e. when there is no nitrogen depletion, can be found in Additional file 6. Finally, the biomass equation was standardized to have a molecular weight of $1 \cdot \mathrm{g} / \mathrm{mmol}$.

The main lipid building-blocks are fatty acid residues. The majority of fatty acid in C. oleaginosus ATCC 20509 is oleic acid $(\mathrm{C} 18: 1)[4,5]$. When growing on glucose, the composition of main fatty acids in C. oleaginosus ATCC 20509 are $25 \%$ hexadecanoic (C16:0), 10\% octadecanoic acid (C18:0), 57\% oleic acid (C18:1), and 7\% linoleic acid $(\mathrm{C} 18: 2)[4,5]$. As specific information about each fatty acid in lipid molecules is not available for C. oleaginosus ATCC 20509, in the model, an artificial acyl-CoA pool for lipid synthesis was formulated. A reaction representing the acyl-CoA pool was introduced: 


$$
0.24952 C_{16: 0}+0.096712 C_{18: 0}+0.55233 C_{18: 1}+0.067963 C_{18: 2} \rightarrow A c y l-C o A_{\text {pool }} .
$$

Coefficients of fatty acids in the acyl-CoA pool reaction represent their weight percentages in the lipid of C. oleaginosus ATCC 20509 according to data in $[4,5]$.

\section{Growth simulation}

Model accuracy was validated using flux balance analysis (FBA) implemented in COBRA Toolbox 2.0.6 [76] in MATLAB environment. Minimum defined medium was used. Unlimited uptake rates of $\mathrm{CO}_{2}, \mathrm{H}_{2} \mathrm{O}, \mathrm{H}^{+}, \mathrm{O}_{2}$, Iron $^{2+}$, phosphate, potassium, sodium, sulphate, and $\mathrm{NH}_{4}$ were allowed. This entailed setting the lower bounds of the corresponding exchange reactions to -1000 , as we used the usual convention of writing the exchange reactions in such way that production corresponds to positive fluxes and consumption to negative ones. These constraints were kept for all simulations.

The gold standard validation technique in GEMs is to compare model prediction to experimental data. In silico growth simulation in the presence of different carbon sources was carried out, for this uptake rate of the corresponding carbon source was constrained to $-10 \mathrm{mmol}$ - $g_{D C W}{ }^{-1} \cdot h^{-1}$. Biomass reaction with experimentally determined content at nitrogen abundant condition was used.

Investigation of lipid synthesis in C. oleaginosus ATCC 20509.

\section{Simulations of growth and lipid production}

We conducted in silico experiments to assess the effect of $\mathrm{C} / \mathrm{N}$ ratio on lipid production in C. oleaginosus ATCC 20509. To compare our prediction with simulation from the response surface method [25], we mimic the experimental setup in [25].

To generate different $\mathrm{C} / \mathrm{N}$ ratios, $\mathrm{C} \mathrm{mmol}$ and $\mathrm{N} \mathrm{mmol}$ were calculated from the data in [25] where nitrogen was set up in the range of [0.1:0.01:0.8] g, carbon was in [1.5: 0.05: 8.5] g with urea and glucose as nitrogen and carbon source, respectively. We assumed a constant uptake of carbon and nitrogen. As reported in [46] after passing a critical $\mathrm{C} / \mathrm{N}$ of $12.83(\mathrm{~mol} / \mathrm{mol})$ or $11(\mathrm{~g} / \mathrm{g})$ the biomass reaches the maximum value of $0.20 \mathrm{~h}^{-1}$. Thus, to simulate lipid production we fixed the growth rate for subsequent optimizations. If the in silico growth rate at the tested $\mathrm{C} / \mathrm{N}$ ratio was higher than $0.2 \mathrm{~h}^{-1}$, we fixed the biomass lower bound and upper bounds to [0.2 $0.9,0.2]$. For growth rates smaller than $0.2 \mathrm{~h}^{-1}$, we fixed the biomass to the maximal predicted values at the corresponding $\mathrm{C} / \mathrm{N}$ ratio. A specific biomass reaction for each $\mathrm{C} / \mathrm{N}$ ratio was used. Lipid formation happens when the cell was subjected to sudden depletion of other nutrients such as nitrogen after growing maximally [5]. To mimic this process, in our simulation, biomass function was constrained to the set values and exchange reaction of lipid body was maximized. We did not constrain biomass when simulating for growth.

To study effects of different carbon sources on growth and lipid production, lower bound and upper bound of each exchange reaction for glucose, fructose, xylose, sucrose, ethanol and glycerol was constrained in each study. To generate different $\mathrm{C} / \mathrm{N}$ ratio the uptake rate was increased gradually in the range of $-[0.1: 5: 100] \mathrm{mmol}$. $g_{D C W}{ }^{-1} \cdot h^{-1}$ for carbon source and of $-[0.1: 1: 10] \mathrm{mmol}$ $\cdot g_{D C W}{ }^{-1} \cdot h^{-1}$ for nitrogen.

\section{Sampling the solution space when shifting $\mathrm{C} / \mathrm{N}$ ratio}

To study how flux distribution change when changing $\mathrm{C} / \mathrm{N}$ ratio, we sampled the solution space at steady state for each $\mathrm{C} / \mathrm{N}$ ratio. Based on $[25,46]$ we selected the $\mathrm{C} / \mathrm{N}$ ratio as $[6,8,10,12,24,30,36,48,60,90,120,180,240]$. To study the effect of carbon concentration on lipid synthesis we simulated lipid production at 3 different $\mathrm{C}(\mathrm{g})$ as $[16,24,32]$ for the same $\mathrm{C} / \mathrm{N}$ range. Minimal medium was used. The solution space at steady state for each $\mathrm{C} / \mathrm{N}$ ratio when optimizing for lipid production with constrained biomass (see Section "Simulations of growth and lipid production") was sampled using gpSampler [77] implemented in COBRA toolbox 2.0.6 [76]. The sample was taken for 5000 sample points with no bias, "maxtime" was $10 \mathrm{~min}$, "maxsteps" was set to $10^{10}$ and 1 thread was used. Sampling results were analyzed as described in [78]. In short, means and standard deviations were calculated from the sampling results to obtain $Z$ scores for each reaction in the central metabolic network. A C/N ratio of $6(\mathrm{~g} / \mathrm{g})$ was used as the reference point to calculate $Z$ scores for fluxes in other $\mathrm{C} / \mathrm{N}$ ratio.

To study the main source of acetyl-coA for lipid synthesis in C. oleaginosus ATCC 20509, we sampled the solution space at steady state for each $\mathrm{C} / \mathrm{N}$ ratio. The $\mathrm{C} / \mathrm{N}$ ratio data from experiment in [46] were used for the simulation. To mimic their experimental setup, uptake rate of nitrogen, in form of urea, was fixed at $-25 \mathrm{mmol}$. $g_{D C W}{ }^{-1} \cdot h^{-1}$. Carbon was gradually increased to generate the desired $\mathrm{C} / \mathrm{N}$ ratio.

\section{Supplementary Information}

The online version contains supplementary material available at https://doi. org/10.1186/s13068-020-01838-1.

Additional file 1. C. curvartum ATCC 20509 genome annotation.

Additional file 2. Details on lipid synthesis pathways. 
Additional file 3. C. oleaginosus and Y. lipolytica orthologs

Additional file 4. Condition-specific biomass generation.

Additional file 5. List of up and down-regulated genes under high and low C/N condition.

Additional file 6 . Biomass component at glucose and unlimited nitrogen condition.

Additional file 7.iNP636_Coleaginosus_ATCC20509 model.

\section{Abbreviations}

GEM: Genome-scale metabolic model; TAG: Triacylglycerol; ACL: ATP-citrate lyase; ACC: Acetyl-CoA carboxylase; FAS: Fatty acid synthetase.

\section{Acknowledgements}

Not applicable.

\section{Authors' contributions}

JS collected RNAseq data. MR, PJS and BN conducted genome annotation and manually inspected ortholog genes. MS-D analyzed the RNAseq data. NP constructed and analyzed model. NP drafted the manuscript. BN, MR, MS-D, GE, and PJS, edited the manuscript. All authors read and approved the manuscript.

\section{Funding}

We gratefully acknowledge financial support from the European Horizon 2020 projects EmPowerPutida (Project reference: 635536) and the Wageningen University IP/OP project. The funders had no role in study design, data collection and analysis, or preparation of the manuscript.

\section{Availability of data and materials}

RNAseq data generated and analyzed during this study were deposited in the European Nucleotide Archive (ENA) repository under accession number PRJEB34237 (url). The model iNP636_Coleaginosus_ATCC 20509 was deposited in BioModels [79] and assigned the identifier MODEL2004170002 and is also provided in this paper as Additional file 7. All other data that support the findings of this study can be found in Additional files 1-7.

\section{Ethics approval and consent to participate}

Not applicable.

\section{Consent for publication}

All authors read and approved the final manuscript.

\section{Competing interests}

The authors declare that they have no competing interests.

\section{Author details}

${ }^{1}$ Laboratory of Systems and Synthetic Biology, Wageningen University \& Research, Wageningen, the Netherlands. ${ }^{2}$ Food and Biobased Research and AlgaePARC, Wageningen University and Research, Wageningen, the Netherlands. ${ }^{3}$ Bioprocess Engineering and AlgaePARC, Wageningen University and Research, Wageningen, the Netherlands. ${ }^{4}$ Department of Ecology and Evolution, University of Lausanne, Swiss Institute of Bioinformatics, 1015 Lausanne, Switzerland.

Received: 30 April 2020 Accepted: 23 November 2020

Published online: 06 January 2021

\section{References}

1. Vasconcelos B, Teixeira JC, Dragone G, Teixeira JA. Oleaginous yeasts for sustainable lipid production-from biodiesel to surf boards, a wide range of "green" applications. Appl Microbiol Biotechnol. 2019;103:1-17.

2. Shi S, Zhao H. Metabolic engineering of oleaginous yeasts for production of fuels and chemicals. Front Microbiol. 2017:8:2185.

3. Ratledge C. Regulation of lipid accumulation in oleaginous micro-organisms. London: Portland Press Limited; 2002.
4. Beopoulos A, Nicaud J-M, Gaillardin C. An overview of lipid metabolism in yeasts and its impact on biotechnological processes. Appl Microbiol Biotechnol. 2011:90(4):1193-206.

5. Ratledge C, Wynn JP. The biochemistry and molecular biology of lipid accumulation in oleaginous microorganisms. Adv Appl Microbiol. 2002;51:1-52

6. Ageitos JM, Vallejo JA, Veiga-Crespo P, Villa TG. Oily yeasts as oleaginous cell factories. Appl Microbiol Biotechnol. 2011;90(4):1219-27.

7. Chi Z, Zheng Y, Ma J, Chen S. Oleaginous yeast cryptococcus curvatus culture with dark fermentation hydrogen production effluent as feedstock for microbial lipid production. Int J Hydrogen Energy. 2011;36(16):9542-50.

8. Ykema A, Verbree EC, Kater MM, Smit H. Optimization of lipid production in the oleaginous yeast apiotrichum curvatum in wheypermeate. Appl Microbiol Biotechnol. 1988;29(2-3):211-8.

9. Zhou W, Gong Z, Zhang L, Liu Y, Yan J, Zhao M. Feasibility of lipid production from waste paper by the oleaginous yeast cryptococcus curvatus. BioResources. 2017;12(3):5249-63.

10. Annamalai N, Sivakumar N, Oleskowicz-Popiel P. Enhanced production of microbial lipids from waste office paper by the oleaginous yeast cryptococcus curvatus. Fuel. 2018;217:420-6.

11. Bracharz F, Beukhout T, Mehlmer N, Bru"ck T. Opportunities and challenges in the development of cutaneotrichosporon oleaginosus atcc 20509 as a new cell factory for custom tailored microbial oils. Microbial Cell Factor. 2017;16(1):178.

12. Yaguchi A, Rives D, Blenner M. New kids on the block: emerging oleaginous yeast of biotechnological importance. AIMS Microbiol. 2017;3:227-47.

13. Meesters PA, Eggink $G$. Isolation and characterization of a $\delta$ - 9 fatty acid desaturase gene from the oleaginous yeast cryptococcus curvatus cbs 570. Yeast. 1996:12(8):723-30.

14. Li Y, Zhao ZK, Bai F. High-density cultivation of oleaginous yeast rhodosporidium toruloides y4 in fed-batch culture. Enzyme Microbial technology. 2007;41(3):312-7.

15. Meng X, Yang J, Xu X, Zhang L, Nie Q, Xian M. Biodiesel production from oleaginous microorganisms. Renewable Energy. 2009;34(1):1-5.

16. Wu S, Zhao X, Shen H, Wang Q, Zhao ZK. Microbial lipid production by rhodosporidium toruloides under sulfate-limited conditions. Biores Technol. 2011;102(2):1803-7.

17. Liu J, Huang $X$, Chen $R$, Yuan M, Liu J. Efficient bioconversion of highcontent volatile fatty acids into microbial lipids by cryptococcus curvatus atcc 20509. Biores Technol. 2017;239:394-401.

18. Liang Y, Cui Y, Trushenski J, Blackburn JW. Converting crude glycerol derived from yellow grease to lipids through yeast fermentation. Biores Technol. 2010;101(19):7581-6.

19. Liu X-Z, Wang Q-M, Goker M, Groenewald M, Kachalkin A, Lumbsch HT, Millanes A, Wedin M, Yurkov A, Boekhout T, et al. Towards an integrated phylogenetic classification of the tremellomycetes. Stud Mycol. 2015:81:85-147.

20. Fell JW, Boekhout T, Fonseca A, Scorzetti G, Statzell-Tallman A. Biodiversity and systematics of basidiomycetous yeasts as determined by largesubunit rdna d1/d2 domain sequence analysis. Int J Syst Evol Microbiol. 2000;50(3):1351-71.

21. Gujjari P, Suh S-O, Coumes K, Zhou JJ. Characterization of oleaginous yeasts revealed two novel species: Trichosporon cacaoliposimilis sp. nov. and trichosporon oleaginosus sp. nov. Mycologia. 2011;103(5):1110-8.

22. Evans CT, Ratledge C. A comparison of the oleaginous yeast, candida curvata, grown on different carbon sources in continuous and batch culture. Lipids. 1983;18(9):623-9.

23. Evans CT, Ratledge C. Induction of xylulose-5-phosphate phosphoketolase in a variety of yeasts grown on $d$-xylose: the key to efficient xylose metabolism. Arch Microbiol. 1984;139(1):48-52.

24. Huang X-F, Wang Y-H, Shen Y, Peng K-M, Lu L-J, Liu J. Using non-ionic surfactant as an accelerator to increase extracellular lipid production by oleaginous yeast cryptococcus curvatus mucl 29819. Biores Technol. 2019;274:272-80.

25. Awad D, Bohnen F, Mehlmer N, Brueck T. Multi-factorial-guided media optimization for enhanced biomass and lipid formation by the oleaginous yeast cutaneotrichosporon oleaginosus. Front Bioeng Biotechnol. 2019;7:54. 
26. G"orner C, Redai V, Bracharz F, Schrepfer P, Garbe D, Bru"ck T. Genetic engineering and production of modified fatty acids by the non-conventional oleaginous yeast trichosporon oleaginosus atcc 20509. Green Chem. 2016;18(7):2037-46

27. Reed JL, Vo TD, Schilling CH, Palsson BO. An expanded genomescale model of escherichia coli k-12 (i jr904 gsm/gpr). Genome Biol. 2003:4(9):54.

28. Close D, Ojumu J. Draft genome sequence of the oleaginous yeast Cryptococcus curvatus atcc 20509. Genome Announc. 2016:4(6):01235-316.

29. Hoff KJ, Lange S, Lomsadze A, Borodovsky M, Stanke M. Braker1: unsupervised rna-seq-based genome annotation with genemark-et and augustus. Bioinformatics. 2015;32(5):767-9.

30. Tehlivets $\mathrm{O}$, Scheuringer K, Kohlwein SD. Fatty acid synthesis and elongation in yeast. Biochimica et Biophy Acta Mol Cell Biol Lipids. 2007;1771(3):255-70.

31. Klug L, Daum G. Yeast lipid metabolism at a glance. FEMS Yeast Res. 2014;14(3):369-88.

32. Fakas S. Lipid biosynthesis in yeasts: A comparison of the lipid biosynthetic pathway between the model nonoleaginous yeast saccharomyces cerevisiae and the model oleaginous yeast yarrowia lipolytica. Eng Life Sci. 2017;17(3):292-302.

33. Garba L, Shukuri Mo M, Nurbaya Os S, Noor Zalih R. Review on fatty acid desaturases and their roles in temperature acclimatisation. J Appl Sci. 2017:17:282-95.

34. Rismani-Yazdi H, Haznedaroglu BZ, Bibby K, Peccia J. Transcriptome sequencing and annotation of the microalgae dunaliella tertiolecta: pathway description and gene discovery for production of next-generation biofuels. BMC Genom. 2011;12(1):148.

35. Capusoni C, Rodighiero V, Cucchetti D, Galafassi S, Bianchi D, Franzosi G, Compagno C. Characterization of lipid accumulation and lipidome analysis in the oleaginous yeasts rhodosporidium azoricum and trichosporon oleaginosus. Biores Technol. 2017;238:281-9.

36. Carman GM, Kersting MC. Phospholipid synthesis in yeast: regulation by phosphorylation. Biochem Cell Biol. 2004;82(1):62-70.

37. Loira N, Dulermo T, Nicaud J-M, Sherman DJ. A genome-scale metabolic model of the lipid-accumulating yeast yarrowia lipolytica. BMC Syst Biol. 2012;6(1):35.

38. van den Berg MA, de Jong-Gubbels P, Kortland CJ, van Dijken JP, Pronk JT, Steensma HY. The two acetyl-coenzyme a synthetases of saccharomyces cerevisiae differ with respect to kinetic properties and transcriptional regulation. J Biol Chem. 1996;271(46):28953-9.

39. Chan SH, Cai J, Wang L, Simons-Senftle MN, Maranas CD. Standardizing biomass reactions and ensuring complete mass balance in genome-scale metabolic models. Bioinformatics. 2017;33(22):3603-9.

40. Dikicioglu D, Kırdar B, Oliver SG. Biomass composition: the "elephant in the room" of metabolic modelling. Metabolomics. 2015:11(6):1690-701.

41. Tchakouteu SS, Chatzifragkou A, Kalantzi O, Koutinas AA, Aggelis G, Papanikolaou S. Oleaginous yeast cryptococcus curvatus exhibits interplay between biosynthesis of intracellular sugars and lipids. Eur J Lipid Sci Technol. 2015;117(5):657-72.

42. Meeuwse P. Production of Fungal Lipids: Kinetic Modeling and Process Design. 2011

43. Yang Y, Sha M. A beginner's quide to bioprocess modes-batch, fed-batch, and continuous fermentation. Technical report, Eppendorf Application Note. 2019

44. Meesters P, Huijberts G, Eggink G. High-cell-density cultivation of the lipid accumulating yeast cryptococcus curvatus using glycerol as a carbon source. Appl Microbiol Biotechnol. 1996;45(5):575-9.

45. Yu X, Zheng $Y$, Xiong $X$, Chen S. Co-utilization of glucose, xylose and cellobiose by the oleaginous yeast cryptococcus curvatus. Biomass Bioenerg. 2014;71:340-9.

46. Ykema A, Verbree $E$, Van Verseveld $H$, Smit H. Mathematical modelling of lipid production by oleaginous yeasts in continuous cultures. Antonie Van Leeuwenhoek. 1986;52(6):491-506.

47. Botham PA, Ratledge C. A biochemical explanation for lipid accumulation in candida 107 and other oleaginous micro-organisms. Microbiology. 1979;114(2):361-75

48. Evans CT, Scragg AH, Ratledge C. Regulation of citrate efflux from mitochondria oleaginous and non-oleaginous yeasts by adenine nucleotides. Eur J Biochem. 1983;132(3):609-15.
49. Zhang H, Zhang L, Chen H, Chen YQ, Chen W, Song Y, Ratledge C. Enhanced lipid accumulation in the yeast yarrowia lipolytica by over-expression of atp: citrate lyase from mus musculus. J Biotechnol 2014;192:78-84.

50. Kerkhoven EJ, Pomraning KR, Baker SE, Nielsen J. Regulation of aminoacid metabolism controls flux to lipid accumulation in yarrowia lipolytica. NPJ Syst Biol Appl. 2016;2:16005.

51. Huerlimann R, Steinig EJ, Loxton H, Zenger KR, Jerry DR, Heimann K. The effect of nitrogen limitation on acetyl-coa carboxylase expression and fatty acid content in chromera velia and isochrysis aff. galbana (tiso). Gene. 2014;543(2):204-11.

52. Kourist R, Bracharz F, Lorenzen J, Kracht ON, Chovatia M, Daum C, Deshpande S, Lipzen A, Nolan M, Ohm RA, et al. Genomics and transcriptomics analyses of the oil-accumulating basidiomycete yeast trichosporon oleaginosus: insights into substrate utilization and alternative evolutionary trajectories of fungal mating systems. MBio. 2015;6(4):00918-1015.

53. Fell DA, Thomas S. Physiological control of metabolic flux: the requirement for multisite modulation. Biochem J. 1995:311(1):35-9.

54. Pfitzner A, Kubicek C, R-ohr M. Presence and regulation of atp: citrate lyase from the citric acid producing fungus aspergillus niger. Archive Microbiol. 1987;147(1):88-91.

55. Potapova IA, El-Maghrabi MR, Doronin SV, Benjamin WB. Phosphorylation of recombinant human atp: citrate lyase by camp-dependent protein kinase abolishes homotropic allosteric regulation of the enzyme by citrate and increases the enzyme activity. allosteric activation of atp: citrate lyase by phosphorylated sugars. Biochemistry. 2000;39(5):1169-79.

56. Moon NJ, Hammond E, Glatz BA. Conversion of cheese whey and whey permeate to oil and single-cell protein 1. J Dairy Sci. 1978;61(11):1537-47.

57. Dobin A, Davis CA, Schlesinger F, Drenkow J, Zaleski C, Jha S, Batut P, Chaisson M, Gingeras TR. Star: ultrafast universal rna-seq aligner. Bioinformatics. 2013;29(1):15-21.

58. Love MI, Huber W, Anders S. Moderated estimation of fold change and dispersion for rna-seq data with deseq2. Genome Biol. 2014;15(12):550.

59. Kim D, Langmead B, Salzberg SL. Hisat: a fast spliced aligner with low memory requirements. Nat Methods. 2015;12(4):357.

60. Koehorst JJ, van Dam JC, Saccenti E, dos Martins Santos VA, SuarezDiez M, Schaap PJ. Sapp: functional genome annotation and analysis through a semantic framework using fair principles. Bioinformatics. 2017;34(8):1401-3.

61. van Dam JC, Koehorst JJ, Vik JO, dos Santos VAM, Schaap PJ, Suarez-Diez M. The empusa code generator and its application to gbol, an extendable ontology for genome annotation. Scientific data. 2019;6(1):1-9.

62. Zdobnov EM, Apweiler R. Interproscan-an integration platform for the signature-recognition methods in interpro. Bioinformatics. 2001;17(9):847-8.

63. Nguyen N-N, Srihari S, Leong HW, Chong K-F. Enzdp: Improved enzyme annotation for metabolic network reconstruction based on domain composition profiles. J Bioinformat Comput Biol. 2015;13(05):1543003.

64. Matlab. Version R2015b. The MathWorks Inc., Natick, Massachusetts. 2015

65. Heirendt L, Arreckx S, Pfau T, Mendoza SN, Richelle A, Heinken A, Haraldsdottir HS, Wachowiak J, Keating SM, Vlasov V, et al. Creation and analysis of biochemical constraint-based models using the cobra toolbox v. 3.0. Nat Protoc. 2019:14(3):639-702.

66. GLPK (GNU Linear Programming Kit). 2009. https://www.gnu.org/softw are/glpk/

67. Pan P, Hua Q. Reconstruction and in silico analysis of metabolic network for an oleaginous yeast, yarrowia lipolytica. PLoS ONE. 2012;7(12):51535.

68. Kavšcek M, Bhutada G, Madl T, Natter K. Optimization of lipid production with a genome-scale model of yarrowia lipolytica. BMC Syst Biol. 2015;9(1):72.

69. Mishra P, Lee N-R, Lakshmanan M, Kim M, Kim B-G, Lee D-Y. Genome-scale model-driven strain design for dicarboxylic acid production in yarrowia lipolytica. BMC Syst Biol. 2018;12(2):12.

70. Nookaew I, Jewett MC, Meechai A, Thammarongtham C, Laoteng K, Cheevadhanarak S, Nielsen J, Bhumiratana S. The genome-scale metabolic model iin800 of saccharomyces cerevisiae and its validation: a scaffold to query lipid metabolism. BMC Syst Biol. 2008;2(1):71.

71. Kanehisa M, Goto S. Kegg: kyoto encyclopedia of genes and genomes. Nucleic Acids Res. 2000;28(1):27-30

72. Teusink B, Passarge J, Reijenga CA, Esgalhado E, Van der Weijden CC, Schepper M, Walsh MC, Bakker BM, Van Dam K, Westerhoff HV, et al. Can 
yeast glycolysis be understood in terms of in vitro kinetics of the constituent enzymes? testing biochemistry. Eur J Biochem. 2000;267(17):5313-29.

73. Raimundo N, Baysal BE, Shadel GS. Revisiting the tca cycle: signaling to tumor formation. Trends Mol Med. 2011;17(11):641-9.

74. Fritzemeier CJ, Hartleb D, Szappanos B, Papp B, Lercher MJ. Erroneous energy-generating cycles in published genome scale metabolic networks: Identification and removal. PLoS Comput Biol. 2017;13(4):1005494.

75. Cooper GM, Hausman RE. The Cell: A Molecular Approach. 4th Edition. 2004

76. Schellenberger J, Que R, Fleming RM, Thiele I, Orth JD, Feist AM, Zielinski DC, Bordbar A, Lewis NE, Rahmanian S, et al. Quantitative prediction of cellular metabolism with constraint-based models: the cobra toolbox v2. 0. Nat Prot. 2011;6(9):1290.

77. Schellenberger J, Palsson BØ. Use of randomized sampling for analysis of metabolic networks. J Biol Chem. 2009;284(9):5457-61.

78. Bordel S, Agren R, Nielsen J. Sampling the solution space in genomescale metabolic networks reveals transcriptional regulation in key enzymes. PLoS Comput Biol. 2010;6(7):1000859.

79. Chelliah V, Juty N, Ajmera I, Ali R, Dumousseau M, Glont M, Hucka M, Jalowicki G, Keating S, Knight-Schrijver V, et al. Biomodels: ten-year anniversary. Nucleic Acids Res. 2015;43(D1):542-8.

80. Qiao K, Wasylenko TM, Zhou K, Xu P, Stephanopoulos G. Lipid production in yarrowia lipolytica is maximized by engineering cytosolic redox metabolism. Nat Biotechnol. 2017;35(2):173.
81. Papanikolaou S, Aggelis G. Lipid production by yarrowia lipolytica growing on industrial glycerol in a single-stage continuous culture. Biores Technol. 2002;82(1):43-9.

82. Fei Q, O'Brien M, Nelson R, Chen X, Lowell A, Dowe N. Enhanced lipid production by rhodosporidium toruloides using different fed-batch feeding strategies with lignocellulosic hydrolysate as the sole carbon source. Biotechnol Biofuels. 2016;9(1):130.

83. Johnson VW, Singh M, Saini VS, Adhikari DK, Sista V, Yadav NK. Utilization of molasses for the production of fat by an oleaginous yeast, rhodotorula glutinis iip-30. J Ind Microbiol. 1995;14(1):1-4.

84. Anschau A, Xavier MC, Hernalsteens S, Franco TT. Effect of feeding strategies on lipid production by lipomyces starkeyi. Biores Technol. 2014;157:214-22

85. Hassan M, Blanc PJ, Granger L-M, Pareilleux A, Goma G. Lipid production by an unsaturated fatty acid auxotroph of the oleaginous yeast apiotrichum curvatum grown in single-stage continuous culture. Appl Microbiol Biotechnol. 1993;40(4):483-8.

\section{Publisher's Note}

Springer Nature remains neutral with regard to jurisdictional claims in published maps and institutional affiliations.
Ready to submit your research? Choose BMC and benefit from:

- fast, convenient online submission

- thorough peer review by experienced researchers in your field

- rapid publication on acceptance

- support for research data, including large and complex data types

- gold Open Access which fosters wider collaboration and increased citations

- maximum visibility for your research: over $100 \mathrm{M}$ website views per year

At BMC, research is always in progress.

Learn more biomedcentral.com/submissions 